Original Research

\title{
Impact of Underground Coal Mining on Regional Landscape Pattern Change Based on Life Cycle: A Case Study in Peixian, China
}

\author{
Jiaxing $\mathrm{Xu}^{1,2}$, Hua Zhao', Pengcheng Yin³, Naishun $\mathrm{Bu}^{4}$, Gang $\mathrm{Li}^{2 *}$ \\ ${ }^{1}$ The National and Local Joint Engineering Laboratory of Internet Applied Technology on Mines, \\ China University of Mining and Technology, Xuzhou, China \\ ${ }^{2}$ Key Laboratory for Land Environment and Disaster Monitoring of National Administration of Surveying, \\ Mapping and Geoinformation, China University of Mining and Technology, Xuzhou, China \\ ${ }^{3}$ Bureau of Natural Resources and Planning of Xuzhou, Xuzhou, China \\ ${ }^{4}$ School of Environmental Science, Liaoning University, Shenyang, China
}

Received: 28 September 2018

Accepted: 7 November 2018

\begin{abstract}
Landscape pattern change (LPC) can provide comprehensive insight into the effects of mining activities on regional ecosystems. This paper examined the impact of coal mining on LPC of Peixian mining area, China. An analysis of LPC was conducted based on GIS-RS technology from 1994 to 2014. The influence of coal mining on the LPC was studied quantitatively from the perspective of life cycle. The following conclusions were drawn:

1) The LPC of the study area changed significantly during the study period. Landscape type index showed a rising trend in fluctuation, and landscape fractal characteristics tended to be simplified and regularized.

2) Landscape indices of cultivated land and waterlogged subsidence zones were highly correlated with annual coal production, and the correlation coefficients were $-0.634,-0.748$ and 0.991 , respectively.

3) The abrupt changes of largest patch index (LPI) and aggregation index (AI) of cultivated land occurred in 1999 and 2001, respectively. The LPI of waterlogged subsidence zones had a sustained upward trend since 1995, but the AI had a significant rising trend in 1997-2006 and 2011-2013.

These results could provide useful guidance on sustainable land use planning and restoring the damaged landscape for underground coal mining areas.
\end{abstract}

Keywords: landscape pattern change; life cycle; Mann-Kendall test; remote sensing; underground coal mines

*e-mail: cumt_lig@126.com 


\section{Introduction}

Human activities have a widespread impact on ecosystems [1]. In the last century, the irresponsible use of natural resources has become one of the most acute problems threatening nature and the environment [2-4]. Therefore, global warming, air pollution, forest and grassland degradation, the irresponsible use of water resources, and the sustainable use of natural resources in all areas have been brought to the agenda [4-7]. Ecologists have improved their understanding of ecosystem processes, including landscape dynamics, energy and material circulation of species and the driving mechanism from different spatial scales [8-9]. In coal mining areas, a special and complex type of geographic area, long-term, large-scale and intense mining inevitably damage the primary geology of coal deposits, occupy and even destroy large amounts of land and cause vegetation degradation, soil erosion by water, a decline in biodiversity and other serious ecological problems [10-12]. Due to the complex nature of the underlying mechanism by which coal mining influences regional ecological environments, it is relatively complicated and challenging to prevent ecological damage, repair disturbed land and improve ecological environments in mining areas.

Life cycle is the sequence of life stages that an organism undergoes from birth to reproduction, ending with the generation of offspring, including birth, growth, maturity, reproduction and recession until death [13]. Since being proposed in 1966 by Raymond Vernon, an American economist, the product life cycle theory has been widely applied to many fields, such as economics, sociology and environmental sciences [14-16]. As a non-renewable resource, the exploitation and utilization of coal mines have an obvious life cycle, including four major phases: formation, development, stability and recession. For a long time, the exploitation and utilization of coal resources also have had a great impact on the ecological environment, e.g., land destruction, vegetation degradation and water pollution [17-19]. The research of applying life cycle theory to a coal mine is helpful in analyzing the forms and levels of environmental pollution and damage caused by coal mining, as well as the ecological risk characteristics in each life cycle phase.

Land use and land cover change (LUCC), a primary result of human activities acting on the Earth's surface, closely correlate with ecological processes such as biodiversity, hydrological processes and ecological functions, having become an important topic for research on global climate and environmental changes [20]. Quantitative landscape information over time is considered the first necessity for understanding consequences from landscape changes [21]. In recent years, various means such as remote sensing (RS) and geographic information system (GIS), as well as a large number of indices representing the geometric features of landscape, have been widely used in the study of landscape pattern changes [8, 22-24]. LPC in coal mining areas are a comprehensive reflection of the impact of mining activities on local ecosystems. Strong anthropogenic disturbances can drastically modify landscape structures and change or degrade landscape functions, exacerbating the deterioration of the ecological environment, which has attracted attention from many scholars [25-26]. A number of studies are focusing on three aspect: quantifying the spatiotemporal variations of land cover and landscape pattern [27-29], identifying the possible driving forces of change [30-31], and assessing the impacts of these changes on the regional eco-environment caused by coal mining [32-34]. But, those studies have focused on land use status, the evolution of landscape pattern, forecasting future, etc., which lacks comprehensive analysis of the correlation between ecological processes and their causes, and neglects environmentally sensitive life cycle development of the study area.

China is one of the largest coal producers in the world and coal production in 2014 was 3.87 billion tons. But more than $92 \%$ of the coal comes from underground mining, causing a large area of surface subsidence. It is estimated that extracting 10 kilotons of coal is associated with subsidence of $0.20-0.33 \mathrm{hm}^{2}$ of land on average. A conservative estimate of greater than $100 \times 10^{4} \mathrm{hm}^{2}$ of land had subsided by the end of 2013 due to coal mining, and subsidence in this area is still increasing at a rate of 3.0-4.7 $\times 10^{4} \mathrm{hm}^{2}$ per year [35]. Coal mining collapse has destroyed the original water system and vegetation, and the physical and chemical properties of soil have been changed, which caused the heterogeneity and fragmentation of landscape structure. Also, coal mining collapses lead large arable lands to become desolate marshes [17, 33]. It is obvious that coal mining collapse has greatly damaged the landscape of the coal mining area, and has also caused a series of ecological and environmental effects, such as air pollution, soil degradation, vegetation carbon storage loss, and change of ecosystem service value [32, 35-37]. Therefore, the research of ecological destruction and landscape restoration in the processes of coal exploitation and utilization have become an important field.

This study used landscape ecology theory, GIS, and geostatistics methods to discuss the impact of underground coal mining on landscape pattern change of the Peixian coal mining area. Landscape types and pattern changes in the study area were quantitatively investigated using remote sensing imagery. At the same time, the relationship between changes of landscape indices and coal production were examined from the perspective of life cycle. The results could provide useful guidance on making sustainable land use planning and restoring the damaged landscape for an underground coal mining area. 


\section{Materials and Methods}

\section{Study Area}

The study area is located on the northern edge of Peixian County, in Xuzhou City (Fig. 1), Jiangsu Province, which lays along the border with Shandong Province between longitudes $116^{\circ} 41^{\prime}$ and $117^{\circ} 09^{\prime} \mathrm{E}$ and latitudes $34^{\circ} 28^{\prime}$ and $34^{\circ} 59^{\prime} \mathrm{N}$. Peibei mining area, a coalproducing region in Peixian, forms an important part of the largest coal production base in eastern China. Coal mining, together with aluminum fabrication, coalto-chemical production and other related industries, accounts for over $55 \%$ of the county's economy. With proven coal reserves of 2.4 billion tons, this mining area was developed in 1970 and production started in 1976. Currently, it has 8 producing mines with a total annual capacity of 12 million tons, with others having been closed due to the downward trend of the coal industry. Local mining activities over the past three decades have caused subsidence of approximately $5000 \mathrm{hm}^{2}$ of land in total. Ensuing ecological problems include serious waterlogging in the subsidence zones, extensive land damage and degradation (especially cultivated land), loss of vegetation, landscape fragmentation and soil contamination. The drastic decline in the ecological quality of land has contributed to concerns regarding ecological safety and food security in the study area.
The subsidence zones induced by coal mining in Peixian can be classified as sloping, seasonally waterlogged or permanently waterlogged, similar to those in Huainan, Huaibei, Yanzhou and Tangshan mining areas, China.

\section{Data Sources and Processing}

Remote sensing images from six periods were used as the data source, including a SPOT-2 panchromatic image acquired on October 5, 1994 (K-J identification 285-280), and Landsat TM (Thematic Mapper) acquired on October 24, 1994 (path 122, row 36), SPOT-4 multispectral image acquired on September 8, 1998 (K-J identification 285-280), SPOT-5 multispectral images acquired on July 21, 2002, June 6, 2006 and October 5, 2010 (K-J identification 285-280), and GF-1 multispectral images acquired on October 24, 2014 (path 603, row 97 and 98). All the images used were produced on summer or autumn days with relatively good weather, and are of ideal quality. The images from 2010 were used as reference images following geometric correction against a 1:10000 topographic map using ERDAS Imagine 9.3, a software application for image processing. Geometric correction of other images was performed using a quadratic equation, with the purpose being reduction in the geometric errors to less than 0.5 pixels, thereby achieving the desired accuracy [38]. The SPOT-2 panchromatic images from 1994,
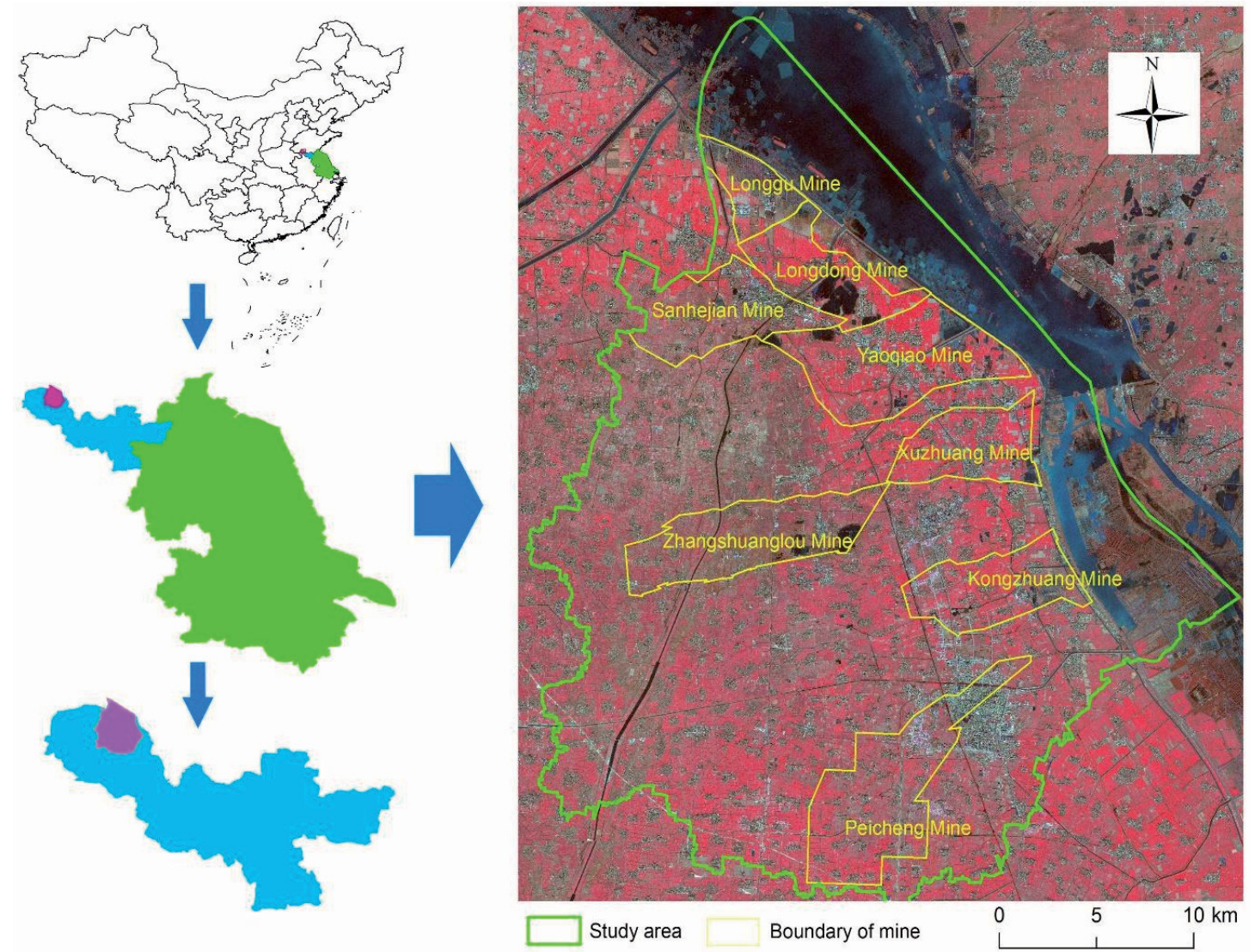

Fig. 1. Location and image map of the study area. 
Table 1. Life cycle for an underground mining area and characteristics of different stages.

\begin{tabular}{|c|c|c|}
\hline Stage & Production characteristics & Ecological effects \\
\hline Planning & $\begin{array}{l}\text { The mine starts production as } \\
\text { planned, and coal production is low. }\end{array}$ & $\begin{array}{l}\text { The land surface is slightly disturbed, and land occupation by industrial } \\
\text { buildings and waste is the main form of land use change. }\end{array}$ \\
\hline Commissioning & $\begin{array}{l}\text { Mining rate and coal production } \\
\text { increase rapidly and earnings grow. } \\
\text { Exploitation activities rapidly } \\
\text { expand in scope. }\end{array}$ & $\begin{array}{l}\text { As coal extraction accelerates and expands in scope, the ground surface } \\
\text { subsides and cultivated land and construction land are typically damaged } \\
\text { and productivity is reduced. Gangue and other waste occupy large amounts } \\
\text { of land. The mining area undergoes significant land use and vegetation } \\
\text { cover change. }\end{array}$ \\
\hline $\begin{array}{c}\text { Stable } \\
\text { exploitation }\end{array}$ & $\begin{array}{l}\text { As the mine enters a stage of } \\
\text { maturity, the production typically } \\
\text { peaks, and the production } \\
\text { capacity and average annual } \\
\text { earnings are stable. }\end{array}$ & $\begin{array}{c}\text { The surface subsides intensely and the subsidence zones tend to be } \\
\text { waterlogged. Cultivated land is severely disturbed. Construction and traffic } \\
\text { land are significantly affected and cracks even occur in some buildings, } \\
\text { posing a threat to human life. The area of land occupied by gangue and } \\
\text { other waste further increases. }\end{array}$ \\
\hline Recession & $\begin{array}{l}\text { The mining area shows } \\
\text { a continuous decrease in resource } \\
\text { reserves, worsening mining } \\
\text { conditions and a decline in economic } \\
\text { benefits. }\end{array}$ & $\begin{array}{l}\text { The surface damage is exacerbated and the waterlogged subsidence zones } \\
\text { expand, with more cultivated land being destroyed and some buildings } \\
\text { flooded. This leads to huge economic loss and further deterioration } \\
\text { of the ecological environment, especially the destruction of land based } \\
\text { ecosystems. }\end{array}$ \\
\hline
\end{tabular}

with a spatial resolution of $10 \mathrm{~m}$, were fused with the TM images from the same year for improving image resolution. To ensure that images of varying resolutions were comparable, the images from the six periods were subsampled at $10 \times 10 \mathrm{~m}$. Based on the national land use classification system and the landscape features common in mining areas situated in the basin regions of eastern China, the landscape in Peibei mining area was divided into 8 types: cultivated land (drylands and paddy fields), forest land, orchard, water, waterlogged subsidence areas, construction land (for mining/industrial sites), traffic land and unused land. Subsequently, the sampled images from each period were interpreted using IDL 8.4 combined with random decision forests, a classification method, in order to extract textural features, spectral characteristics and other information. Data for waterlogged subsidence zones were obtained by estimating mining subsidence. The accuracy of classification was then assessed through comparisons with the land use survey data from the same periods, high-resolution images, and GPS data, as well as interviews with local residents.

\section{Life Cycle of Underground Coal Mining Area and its Characteristics}

By summarizing the existing research results and the processes of coal exploitation in China, the whole life cycle of an underground coal mining area can be divided into four phases: planning period, commissioning period, stable exploitation period and recession period. A coal mine typically has varied production characteristics during different stages, and the mining-induced disturbances to the local landscape pattern and ecosystems also differ across its life cycle [13]. Table 1 shows the life cycle for an underground mining area and the characteristics of different periods.
Based on the production characteristics of Peibei mining area and existing methods for identifying stages of a mining area's life cycle [13, 39], this study found that Peibei mining area is currently in the stable exploitation period, where mining is taking place continuously on a large scale. The original ecological balance in this area has been disturbed and land subsidence is occurring rapidly. Land use and vegetation cover is changing drastically, and the initial stable ecosystems are becoming vulnerable. Fig. 2 shows the life cycle and coal production curves of Peibei mining area. In Fig. 2, the coal production had declined during 2010-2014. China now is reducing overcapacity (excess capacity) and implementing eco-civilization construction. As a result, the decline in coal production is largely due to policy rather than resource exhaustion. Therefore, the recession period is uncertain.

\section{Indices of Landscape Pattern}

LPC is the concrete manifestation of the landscape heterogeneity of patches with different sizes and shapes,

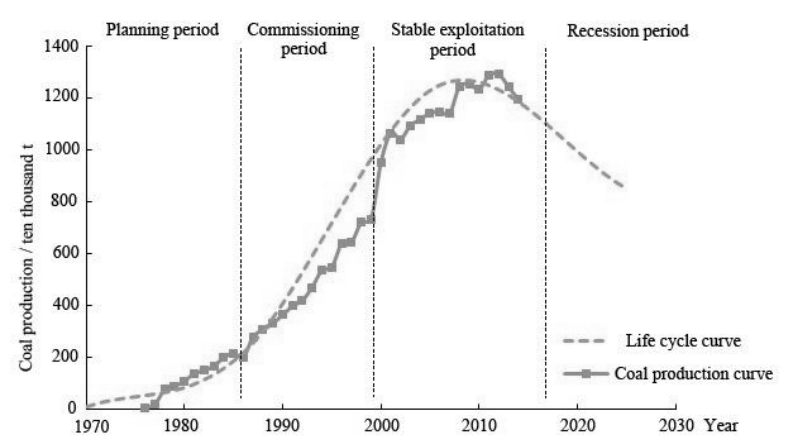

Fig. 2. Coal production and life cycle curves of Peibei mining area. 
and it is also the result of various ecological processes on different scales [40]. The process of coal mining greatly affects the size, shape and connectivity of the landscape, and indirectly affects the ecological stability and sustainable development potential of a coal mining area. The largest patch index (LPI) and aggregation index (AI) were selected to analyze the landscape structure and spatial change of mining area according to characteristics of landscape index [41], and it tried to explore the influence of coal mining on landscape pattern change.

(1) LPI is used to describe the matrix or dominant type of landscape. Changes in its value are associated with changes in the intensity and frequency of disturbance, which can reflect the direction and intensity of human activities [42]. The equation is as follows:

$$
\mathrm{LPI}=\frac{\operatorname{Max}\left(a_{1}, a_{2}, \ldots, a_{n}\right)}{A}(100)
$$

...where LPI denotes the largest patch index (\%), whose value falls within the interval of 0-100; $\operatorname{Max}\left(a_{1}, a_{2}, \ldots, a_{\mathrm{n}}\right)$ represents the area of the largest patch in a landscape $\left(\mathrm{m}^{2}\right)$; and $\mathrm{A}$ is the total area of a particular landscape type $\left(\mathrm{m}^{2}\right)$.

(2) AI describes the spatial distribution of, and the spatial relationships between, different types of patches, reflecting their tendency toward spatial aggregation [43]. It is given by:

$$
\mathrm{AI}=\frac{y_{i i}}{\max g_{i i}}(100)
$$

...where $g_{i i}$ is the number of nodes between pixels in type $i$ patch based on the monotonic method, and max $g_{i i}$ is the maximum number of nodes between pixels in type $i$ patch. A smaller AI value indicates a higher fragmentation level of a certain type of patch, while a higher AI value suggests a greater extent of aggregation.

\section{Detection Methods of LPC}

The Mann-Kendall test, a non-parametric statistical method for trend analysis, can offer a broad detection range and high quantification capability, and is independent of sampling distribution [44]. With these advantages, the Mann-Kendall trend test has been widely used to analyze long-term time series of hydrological, climate, vegetation and pollution data [45-47]. For a time series X with n samples, the ordered sequence can be constructed as shown below:

$$
S_{k}=\sum_{i=1}^{k} r_{i}, \quad r_{i}=\left\{\begin{array}{cc}
1 & x_{i}>x_{j} \\
0 & \text { else }
\end{array} \quad j=1,2, \ldots, i\right.
$$

...where $S_{k}$ is the cumulative number of terms whose values are greater at time $i$ than at time $j$. Assuming that the time series are stochastically independent, a statistic can be defined by:

$$
U F_{k}=\frac{S_{k}-E\left(S_{k}\right)}{\sqrt{\operatorname{Var}\left(S_{k}\right)}} \quad k=1,2, \ldots, n
$$

...where $E\left(S_{k}\right)$ and $\operatorname{Var}\left(S_{k}\right)$ are the mean and variance of $S_{k}$, respectively. If $x_{1}, x_{2}, \ldots, x_{n}$ are mutually independent, continuous and identically distributed, then the following applies:

$$
E\left(S_{k}\right)=\frac{k(k-1)}{4}, \quad \operatorname{Var}\left(S_{k}\right)=\frac{k(k-1)(2 k+5)}{72}
$$

In this case, $\mathrm{UF}_{\mathrm{k}}$ has the standard normal distribution and $U F_{1}=0$. The process can be repeated in the reverse order $\left(x_{n}, x_{n-1}, \ldots ., x_{1}\right)$ of $\mathrm{X}$. The statistic for the inverse sequence, denoted as $U B_{k}$, can be described by equation:

$$
U B_{k}=-U F_{k} \quad k=n, n-1, \ldots, 1
$$

...where $U B_{1}=0$. For a significance level of $\alpha=0.05$, $u_{0.05}= \pm 1.96$. $U F_{k}$ and $U B_{k}$ curves can then be plotted. If $U F_{k}>0$, there is an upward trend in the series; otherwise, the trend is downward. If certain critical lines are exceeded, the upward or downward trend is marked. If the two curves intersect at point(s) between the critical lines, the time at an intersection point represents the starting point of an abrupt change.

\section{Results and Discussion}

\section{Dynamic Change of Landscape Pattern \\ Landscape Type Changes}

Based on the images from the six periods, land cover in the study area was classified into 6 landscape categories using random decision forests (Fig. 3). The accuracies of classification are summarized in a confusion matrix (Table 2). The overall accuracies of classification for 1994, 1998, 2002, 2006, 2010 and 2014 were $0.84,0.86,0.85,0.91,0.91$ and 0.87 , respectively, and corresponding kappa coefficients of $0.82,0.84$, $0.83,0.91,0.9$ and 0.85 , respectively. The area of each landscape type was counted (Table 3). As can be seen in Table 3, the study area experienced significant landscape changes between 1994 and 2014, primarily shrinkage of cultivated land, forest land and unused land. The net reductions in their areas were $6752.99 \mathrm{hm}^{2}, 2560.13 \mathrm{hm}^{2}$ and $2422.12 \mathrm{hm}^{2}$, respectively. By contrast, the areas of construction land and subsidence zones increased rapidly, with net increases of $11888.30 \mathrm{hm}^{2}$ and $1188.93 \mathrm{hm}^{2}$, respectively. In terms of average annual rate of change, the area of waterlogged subsidence zones changed at the fastest rate during 1994-2014, followed 


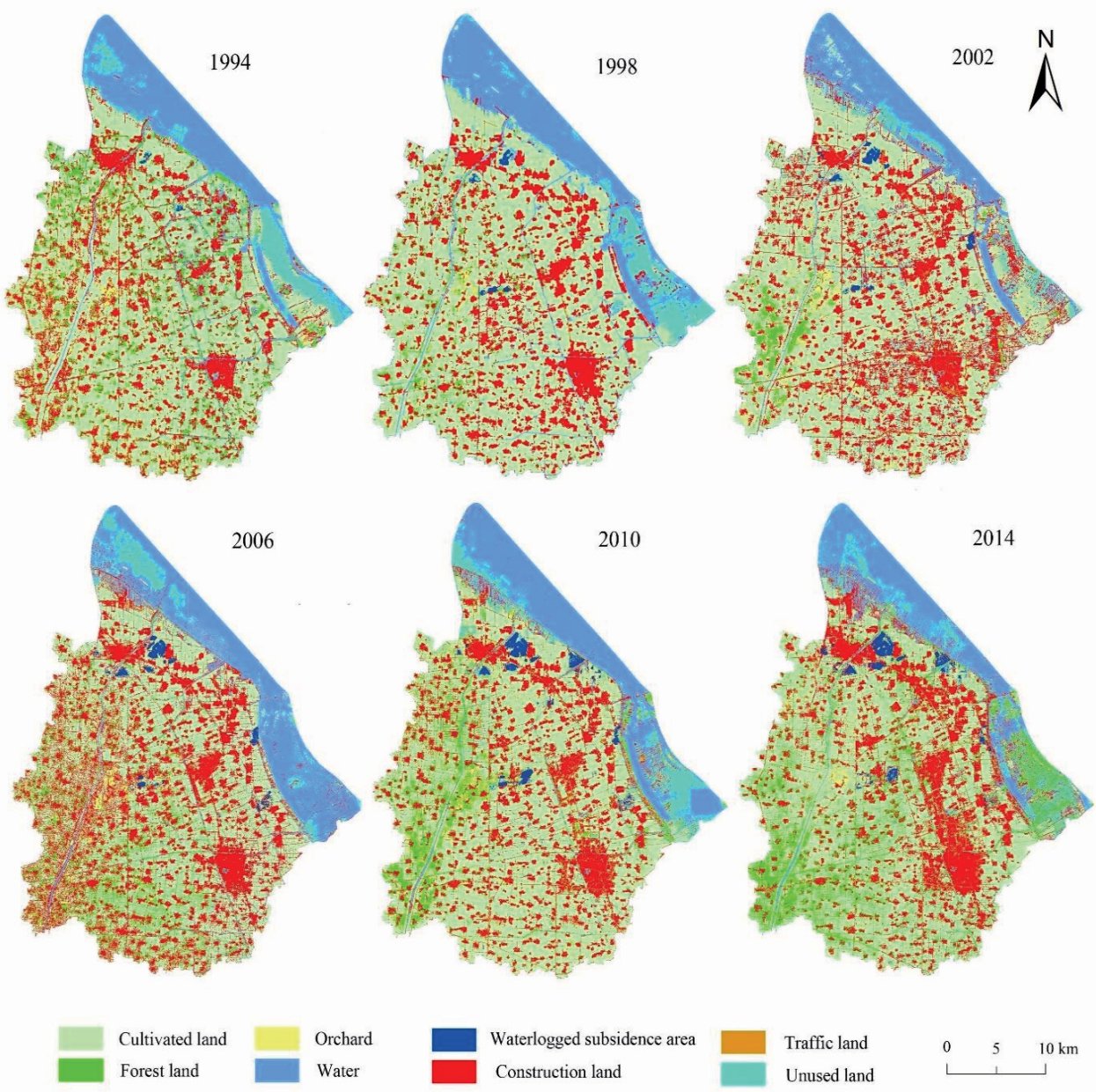

Fig. 3. Landscape classification of Peibei mining area between 1994 and 2014.

by forest land and unused land (Table 3). Cultivated land and construction land (for mining/industrial sites) showed significant net increases in areas, but their annual rates of change were not significantly high, since their original areas were large. The area of construction land increased steadily over the study period, with the annual rate of increase peaking at $6.74 \%$ during 2002-2006.

Table 2. Accuracy assessment of the classified images between 1994 and 2014

\begin{tabular}{|c|c|c|c|}
\hline Year & Data type & $\begin{array}{c}\text { Overall } \\
\text { accuracy of (\%) }\end{array}$ & $\begin{array}{c}\text { Kappa } \\
\text { coefficient }\end{array}$ \\
\hline 1994 & $\begin{array}{c}\text { SPOT-2 + Landsat } \\
\text { TM }\end{array}$ & 0.84 & 0.82 \\
\hline 1998 & SPOT-4 & 0.86 & 0.84 \\
\hline 2002 & SPOT-5 & 0.85 & 0.83 \\
\hline 2006 & SPOT-5 & 0.91 & 0.91 \\
\hline 2010 & SPOT-5 & 0.91 & 0.9 \\
\hline 2014 & GF-1 & 0.87 & 0.85 \\
\hline
\end{tabular}

\section{Landscape Pattern Changes}

Changes in the two aforementioned indices of landscape pattern were calculated using FRAGSTATS 3.3. The results are provided in Table 4. As can be seen in Table 4, cultivated land LPI was 19.57 in 1994 and 26.91 in 1998. Between 1994 and 1998, when the coal mines in Peibei mining area were in the commissioning period, cultivated land began to be disturbed, but still remained the dominant landscape. Between 2002 and 2006, when the coal mines were in the stable exploitation period, the intense coal mining and urban sprawl rapidly diminished cultivated land and reduced its dominance, as indicated by the continual decline in its LPI. From 2010 to 2014, the cultivated land area increased as a result of the relocation of local villages, land reclamation, and other projects implemented to repair subsided land. The steady rise in cultivated land LPI suggests an increase in its dominance among other landscapes. The LPI of construction land shows fluctuations and an overall upward trend. The growth in its dominance can be attributed to urban sprawl and an increase in the number of industrial and mining enterprises. The AI of cultivated land exhibits an overall downward trend despite the growth at the beginning, 
Table 3. Landscape type changes in Peibei mining area between 1994 and $2014\left(\mathrm{hm}^{2}\right)$.

\begin{tabular}{|c|c|c|c|c|c|c|}
\hline Yand use type & 1994 & 1998 & 2002 & 2006 & 2010 & 2014 \\
\hline Cultivated land & 41982.04 & 46313.62 & 46196.22 & 43075.48 & 37563.96 & 35229.05 \\
\hline Forest land & 7263.39 & 4351.12 & 4290.42 & 3130.02 & 4317.64 & 4703.26 \\
\hline Orchard & 436.03 & 445.28 & 450.40 & 483.72 & 570.10 & 622.78 \\
\hline Water & 14123.74 & 13755.58 & 13939.72 & 13482.79 & 13600.86 & 12458.79 \\
\hline Waterlogged subsidence area & 56.38 & 315.73 & 612.21 & 871.64 & 1135.29 & 1245.31 \\
\hline Construction land & 15035.20 & 15476.34 & 16480.78 & 20925.53 & 24541.39 & 26923.50 \\
\hline Traffic land & 1797.51 & 1875.33 & 1824.29 & 1731.67 & 1756.17 & 1933.73 \\
\hline Unused land & 6485.46 & 4646.76 & 3385.72 & 3478.91 & 3694.35 & 4063.34 \\
\hline
\end{tabular}

while construction land shows fluctuations and an overall upward trend in AI (Fig. 4a).

The LPI and AI curves reveal that forest land, gardens and traffic land accounted for relatively small portions of the mining area. Since the three landscape types were disturbed to a great extent by human activities, they were severely dissected into discontinuous patches. From 1994 to 2010, the LPI and AI of unused land decreased consistently, suggesting that some unused land was developed and utilized. From 2010 to 2014, the LPI and AI of unused land increased, conceivably due to the fact that the conversion of terrestrial to aquatic ecosystems in mining-induced subsidence zones caused an increase in the area of boggy land. Fig. 4b) shows that the LPI of waterlogged subsidence zones had a sustained upward trend, while the AI shows fluctuations and an overall increase. On one hand, the waterlogged subsidence zones gradually expanded as the intense mining continued, thus elevating LPI. On the other hand, as the subsidence zones were properly integrated into surrounding landscapes or modified to wetland landscapes during the land reclamation project, the extent of landscape aggregation consistently increased.

\section{Detection of Abrupt Changes of Landscape Indices}

According to the above analysis, the cultivated land and waterlogged subsidence zones in the study area experienced the most drastic changes in terms of LPI and AI, therefore, the Mann-Kendall trend test in this study focused only on the landscape indices of these two land use types. As the index values were calculated for 6 separate years, a first-order univariate gray model, denoted as GM $(1,1)$, was fitted to the data points for each index and then a series for 21 continuous years was obtained by interpolation [48]. Subsequently, the Mann-Kendall trend test was performed to

Table 4. Changes in landscape indices of Peibei mining area between 1994 and 2014.

\begin{tabular}{|c|c|c|c|c|c|c|c|c|c|}
\hline $\begin{array}{l}\text { Landscape } \\
\text { indices }\end{array}$ & Year & $\begin{array}{l}\text { Cultivated } \\
\text { land }\end{array}$ & Forest land & Orchard & Water & $\begin{array}{c}\text { Waterlogged } \\
\text { subsidence area }\end{array}$ & $\begin{array}{c}\text { Construction } \\
\text { land }\end{array}$ & Traffic land & $\begin{array}{l}\text { Unused } \\
\text { land }\end{array}$ \\
\hline \multirow{6}{*}{$\begin{array}{l}\text { Largest patch } \\
\text { index (LPI) }\end{array}$} & 1994 & 19.57 & 0.12 & 0.18 & 12.08 & 0.05 & 1.00 & 0.02 & 2.26 \\
\hline & 1998 & 26.91 & 0.04 & 0.10 & 7.67 & 0.12 & 1.74 & 0.02 & 4.51 \\
\hline & 2002 & 6.77 & 0.19 & 0.07 & 6.51 & 0.19 & 3.03 & 0.09 & 2.43 \\
\hline & 2006 & 4.67 & 0.07 & 0.11 & 14.11 & 0.21 & 2.09 & 0.01 & 1.24 \\
\hline & 2010 & 13.65 & 0.41 & 0.08 & 11.97 & 0.34 & 2.68 & 0.11 & 0.61 \\
\hline & 2014 & 28.33 & 0.75 & 0.03 & 9.35 & 0.34 & 3.98 & 0.04 & 1.01 \\
\hline \multirow{6}{*}{$\begin{array}{l}\text { Aggregation } \\
\text { index (AI) }\end{array}$} & 1994 & 89.80 & 63.12 & 51.37 & 84.01 & 86.35 & 63.82 & 38.77 & 82.46 \\
\hline & 1998 & 94.27 & 67.31 & 75.35 & 86.76 & 90.62 & 86.40 & 50.85 & 89.59 \\
\hline & 2002 & 86.02 & 67.75 & 46.99 & 81.18 & 91.57 & 73.08 & 40.38 & 71.81 \\
\hline & 2006 & 78.59 & 40.45 & 34.90 & 84.49 & 88.16 & 64.74 & 14.45 & 59.43 \\
\hline & 2010 & 85.03 & 50.45 & 38.96 & 85.31 & 90.43 & 67.16 & 29.83 & 37.06 \\
\hline & 2014 & 80.77 & 46.17 & 43.35 & 82.64 & 88.22 & 66.77 & 24.36 & 40.85 \\
\hline
\end{tabular}


a)

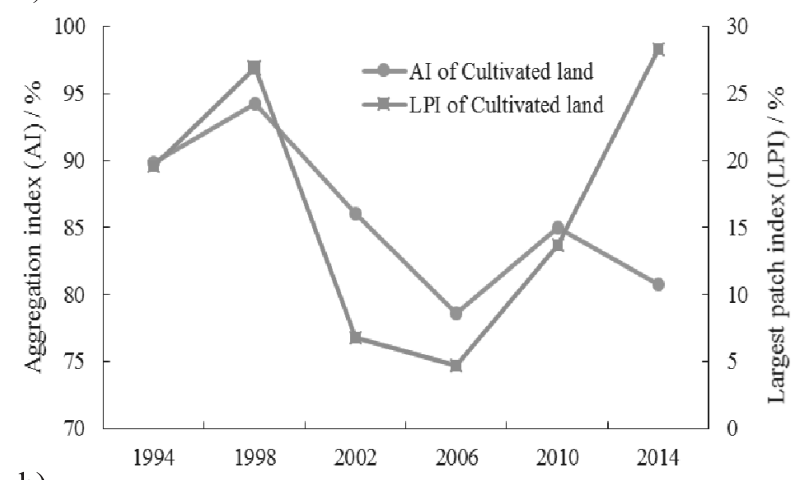

b)

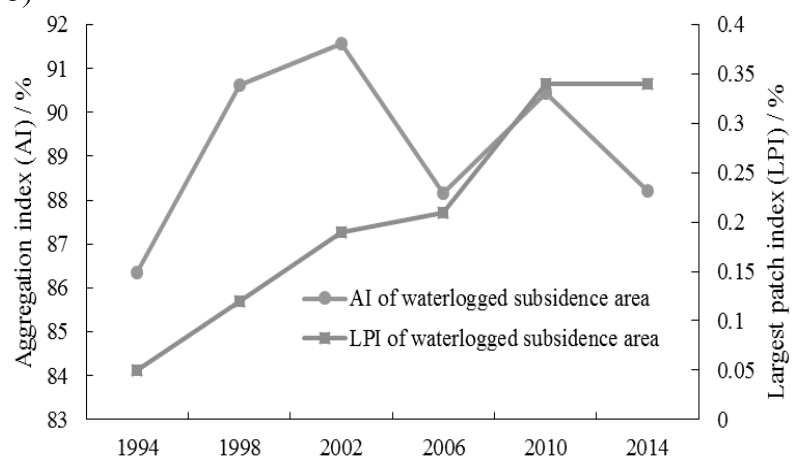

Fig. 4. Location and image map of the study area; landscape index changes of the cultivated land and waterlogged subsidence area in 1994-2014: a) Description of landscape indices changes of the cultivated land; b) Description of landscape indices changes of waterlogged subsidence area.

detect abrupt changes in the LPI and AI of cultivated land and waterlogged subsidence zones. The test results are presented in Fig. 5, with the significance level set at 0.05 . Fig. 5a) shows that the $U F_{k}$ and $U B_{k}$ curves intersect around the year 2001, and the intersection point lies within the confidence interval, indicating that the extent of cultivated land aggregation in the mining area began to change abruptly in approximately 2001 . A strong downward trend in AI began in 2003, suggesting that cultivated land was typically fragmented. The results of the trend test for cultivated land LPI (Fig. 5b) reveal that the $U F_{k}$ and $U B_{k}$ curves intersect around the year 1999, which implies that the dominance of cultivated land began to change abruptly in 1999 . A decline continued until 2010, when LPI began to rise slightly.

As shown in Fig. 5c), there was no abrupt change in the AI of waterlogged subsidence zones, exhibiting a strong upward trend from 1997 to 2006, and from 2011 to 2013. In terms of LPI, the $U F_{k}$ and $U B_{k}$ curves intersect at a point outside the confidence interval; however, the $U F_{k}$ curve moves upward across the upper boundary of the confidence interval $(\alpha=0.05)$, as shown in Fig. 5d). This suggests that the area of waterlogged subsidence zones expanded continuously after 1995. Moreover, the AI curve for waterlogged subsidence zones is relatively flat during 2006 to 2011.

\section{Discussion on Impact of Coal Mining on LPC}

It is important to understand the process of landscape pattern change and its driving factors, which can make people realize that their actions influence the ecological environment, and contributes to rational utilization of land resources, ecological environmental protection and optimizing the development policy [49-50]. Coal mining is one of the typical strong interference ways of human activities on the ecological environment. This paper could be used as a reference for researching how underground coal mining affects the landscape pattern change. In this study, we quantified landscape patterns during the past 20 years and described how the landscape pattern had been changed in response to underground coal mining.

Coal mining has a serious influence on landscape pattern change of mining area. The correlations between annual coal production over the study period and the LPI and AI of cultivated land and waterlogged subsidence zones were analyzed. The corresponding correlation coefficients were $-0.634,-0.748,0.911$ and 0.191 , respectively, demonstrating that the landscape indices of the two land use types, in particular the LPI of waterlogged subsidence zones, correlated highly with coal production. According to the analysis of abrupt changes in the landscape indices, the LPI and AI of cultivated land began to change abruptly in 1999 and 2001, respectively, moving downward rapidly, indicating that the mining activities first affected the dominance of cultivated land. Later, as the mining activities intensified, the extent of cultivated land aggregation began to be affected, followed by the regional landscape pattern. According to the life cycle stage of coal mining area, the production from each coal mine in the study area peaked for the first time around 2001, indicating that the mines entered a stable exploitation period. During this period, cultivated land was heavily disturbed and its aggregation extent decreased sharply. Consequently, an abrupt change in the AI of cultivated land began in 2001. Due to the policy of reducing overcapacity and implementing eco-civilization construction, coal production declined during 2010-2014 (Fig. 2). Therefore, the decline is temporary and it does not mean that the mining areas enter the recession period.

In most cases, the ecological effects on the surface lag behind the underground mining activities [32]. Since the study area is located in a high groundwater table plain area of eastern China, the subsided land over goafs is likely to be waterlogged, and the resulting waterlogged subsidence zones typically expand continuously with the increase of mining scale and intensity. The LPI curve for the positive sequence moves upward across the upper boundary of the confidence interval $(\alpha=0.05)$ (Fig. 5d), implying that the waterlogged subsidence zones expanded continuously after 1995. Taken together with the changes in mining intensity and waterlogged 
a)

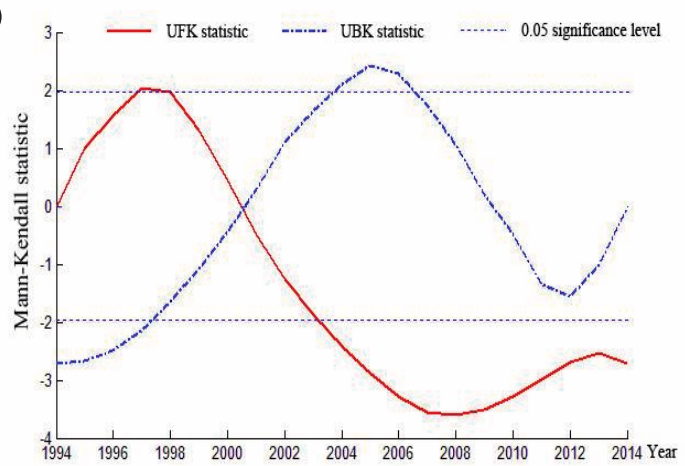

c)

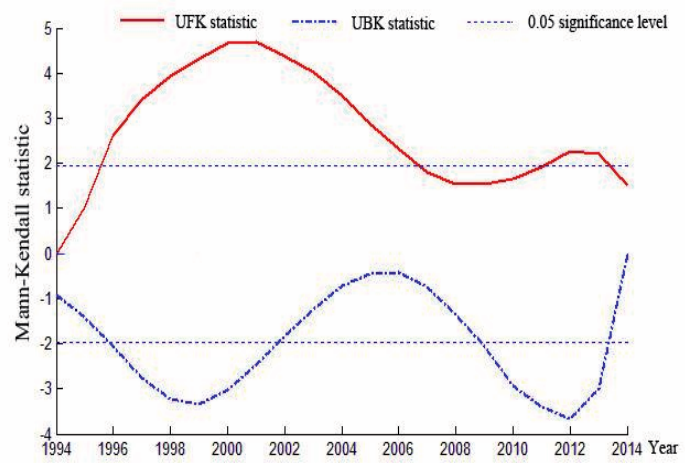

b)

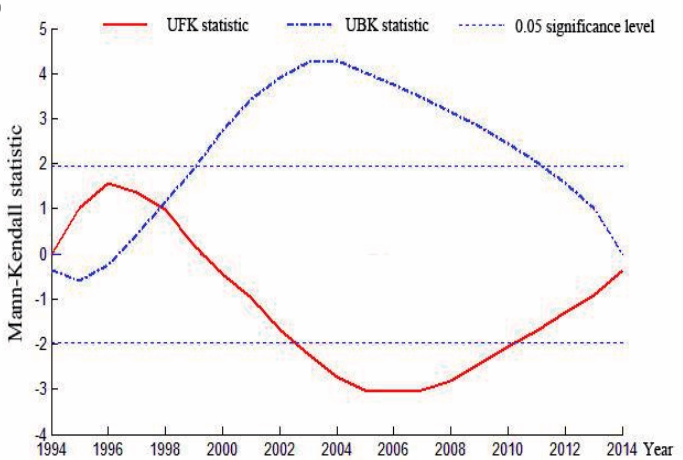

d)

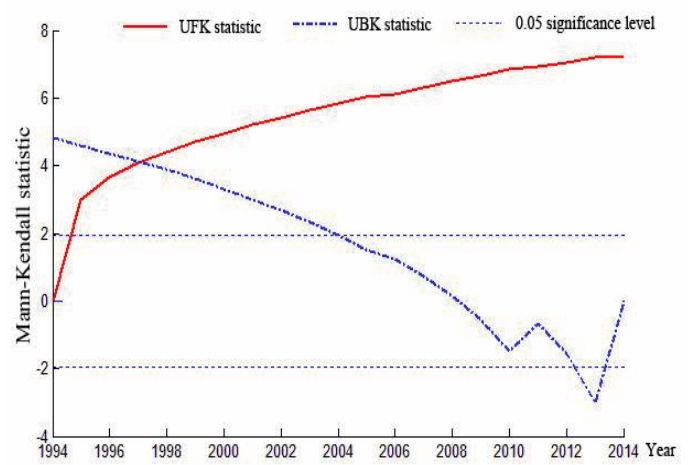

Fig. 5. Mann-Kendall trend test results for cultivated land and waterlogged subsidence zones in Peibei mining area: a) Description of AI abrupt test of cultivated land; b) Description of LPI abrupt test of cultivated land; c) Description of AI abrupt test of waterlogged subsidence zones; d) Description of LPI abrupt test of waterlogged subsidence zones.

subsidence zones, this demonstrates that coal mining is the direct cause of surface subsidence. As the mining activities intensified, the subsidence zones expanded outward, and the directionality of water spread over these zones is the same as mining progression. In recent years, the implementation of green coal mining (e.g., gangue backfilling or grouting in separated-bed for new goafs) and land reclamation and restoration projects have been found to slow down the rate of surface subsidence and effectively increase the cultivated land and improve the ecological environment of the study area [51]. The AI of waterlogged subsidence zones did not change significantly between 2006 and 2011, primarily due to the fact that the waterlogged subsidence zones were effectively restored by land reclamation, ecological restoration and other projects.

Due to the complexity and specificity of the research objective, this study still needs further improvements in the following areas: The research data from different satellite sensors have varied spatial resolutions and spectral information. Despite the efforts to minimize error in classification (image fusion, subsampling and field survey), the information regarding LPC extracted from the data still contains errors, due to the essential differences between multi-source remote sensing data. In addition to mining-induced disturbances, the complex process of LPC is also influenced by regional economy, population, and urbanization. As the present study only looked at the effects of coal mining on LPC, further research is needed into the driving mechanism behind LPC. Furthermore, this paper only analyzed the Peibei mining area empirically, thus the results of the case study have some limited theoretical and practical significance for land reclamation and restoration of the damaged landscapes and ecosystems in high groundwater mining areas. Follow-up studies will address the above problems to improve the theory and practice of landscape ecological effects assessment and ecological restoration of the coal mining subsidence area.

\section{Conclusions}

This paper described a case study performed on an underground coal mining area in a plain region, Xuzhou Peibei coal mining area. Based on the remote sensing images from 1994 to 2014, the characters and changes of landscape pattern were analyzed quantitatively and spatially, and how the LPC in response to underground coal mining was measured with the methods of GIS, landscape ecology and geostatistics. The main conclusions are as follows:

1) The landscape structure and landscape pattern of the study area changed significantly during the past 20 years. Landscape presented a fragmental trend, and 
landscape fractal characteristics tended to simplify and regularize.

2) The LPC has a strong correlation with coal mining. The corresponding correlation coefficients of the LPI and AI of cultivated land and waterlogged subsidence zones were $-0.634,-0.748$ and 0.911 , respectively.

3) The abrupt changes of LPI and AI of cultivated land occurred in 1999 and 2001, respectively. The AI of waterlogged subsidence zones had a significant rising trend in two periods, 1997-2006 and 2011-2013, but no significant change in 2006-2011 years, and the LPI of waterlogged subsidence zones was increasing gradually over the whole period. Through life cycle analysis of the coal mine, land subsidence induced by continuous large-scale underground coal mining and ensuing waterlogging, damage to cultivated land and rapid urbanization were found to be the main causes of LPC.

Our results could provide useful guidance for making landscape protection planning and repairing damaged landscapes for underground coal mining areas.

\section{Acknowledgements}

This research was jointly supported by the National Natural Science Foundation of China (Nos. 41401610, 51874278), the 'Five-twelfth' National Science and Technology Support Program (No. 2012BAB11B06), the National Key R\&D Program of China (No. 2017YFC0804401), the Land Resources Science and Technology Planning Project of Jiangsu Province (No. 2016028) and the Scientific Research Fund of Liaoning Provincial Education Department (No. LYB201615).

\section{Conflict of Interest}

The authors declare no conflict of interest.

\section{References}

1. JAIN M., DIMRI A.P., NIYOGI D. Land-air interactions over urban-rural transects using satellite observations: analysis over Delhi, India from 1991-2016. Remote Sensing. 9 (12), $1283,2017$.

2. CETIN M., SEVIK H., CANTURK U., CAKIR C. Evaluation of the recreational potential of Kutahya urban forest. Fresenius Environmental Bulletin, 27 (5), 2629, 2018.

3. YUAN J., COHEN M.J., KAPLAN D.A., ACHARYA S., LARSEN L.G., NUNGESSER, M.K. Linking metrics of landscape pattern to hydrological process in a lotic wetland. Landscape Ecology, 30 (10), 1893, 2015.

4. CETIN M. ZEREN I., SEVIK H., CAKIR C., AKPINAR H. A study on the determination of the natural park's sustainable tourism potential. Environmental Monitoring and Assessment, 190 (3), 167, 2018.

5. YUCEDAG C., KAYA L.G., CETIN M. Identifying and assessing environmental awareness of hotel and restaurant employees' attitudes in the Amasra District of Bartin. Environmental Monitoring and Assessment, 190 (2), 60, 2018.

6. CETIN M., SEVIK H. Evaluating the recreation potential of Ilgaz Mountain National Park in Turkey. Environmental Monitoring and Assessment, 188 (1), 52, 2016.

7. CETIN M. Evaluation of the sustainable tourism potential of a protected area for landscape planning: a case study of the ancient city of Pompeipolis in Kastamonu. International Journal of Sustainable Development and World Ecology, 22 (6), 490, 2015.

8. ZHANG J., ZHU Y., FAN F. Mapping and evaluation of landscape ecological status using geographic indices extracted from remote sensing imagery of the Pearl River Delta, China, between 1998 and 2008. Environmental Earth Sciences, 75 (4), 327, 2016.

9. KAYA E., AGCA M., ADIGUZEL F., CETIN M. Spatial data analysis with $\mathrm{R}$ programming for environment. Human and Ecological Risk Assessment, 24 (1), 1, 2018.

10. LI F., LIU X., ZHAO D., WANG B., JIN J., HU D. Evaluating and modeling ecosystem service loss of coal mining: a case study of Mentougou district of Beijing, China. Ecological Complexity, 8 (2), 139, 2011.

11. STOJILJKOVIC E., GROZDANOVIC M., MARJANOVIC D. Impact of the underground coal mining on the environment. Acta Montanistica Slovaca, 19 (1), 6, 2014.

12. PANDEY B., AGRAWAL M. SINGH S. Coal mining activities change plant community structure due to air pollution and soil degradation. Ecotoxicology, 23 (8), 1474, 2014.

13. DAI W., DONG J., YAN W., XU J. Study on each phase characteristics of the whole coal life cycle and their ecological risk assessment: a case of coal in China. Environmental Science and Pollution Research, 24 (2), 1296, 2017.

14. VERNON R. International investment and international trade in the product cycle. The Quarterly Journal of Economics, 80 (2), 190, 1966.

15. LIANG X.Y., WANG Z.H., ZHOU Z.J., HUANG Z.Y., ZHOU J.H., CEN K. Up-to-date life cycle assessment and comparison study of clean coal power generation technologies in China. Journal of Clean Production, 39 (5), 24, 2013.

16. WOODS J.S., DAMIANI M., FANTKE P., HENDERSON A.D., JOHNSTON J.M., BARE J., SALA S., SOUZA D.M., PFISTER S., POSTHUMA L., ROSENBAUM R.K., VERONES F. Ecosystem quality in LCIA: status quo, harmonization, and suggestions for the way forward. The International Journal of Life Cycle Assessment, 23, 1995, 2017.

17. LI L., WU K., ZHOU D.W. Extraction algorithm of mining subsidence information on water area based on support vector machine. Environmental Earth Sciences, 72 (10), 3991, 2014.

18. LIBERDA E.N., TSUJI L.J., PELTIER R.E. Mining in subarctic Canada: airborne $\mathrm{PM}_{2.5}$ metal concentrations in two remote First Nations communities. Chemosphere, 139 (4), 452, 2015.

19. BUKOWSKI P. Evaluation of water hazard in hard coal mines in changing conditions of functioning of mining industry in upper Silesian coal basin - USCB (Poland). Archives of Mining Sciences, 60 (2), 455, 2015.

20. DANG A.N., KAWASAKI A. Integrating biophysical and socio-economic factors for land-use and land-cover change projection in agricultural economic regions. Ecological Modelling, 344, 29, 2017. 
21. FAN Q.D., DING S.Y. Landscape pattern changes at a county scale: A case study in Fengqiu, Henan Province, China from 1990 to 2013. Catena, 137, 152, 2016.

22. LIU L., ZHOU J.S. Analyzing Ecological Functions in Coal Mining Cities Based on RS and GIS. Polish Journal of Environmental Studies, 27 (3), 1165, 2018.

23. CETIN M. Using GIS analysis to assess urban green space in terms of accessibility: case study in Kutahya. International Journal of Sustainable Development and World Ecology, 22 (5), 420, 2015.

24. RASTANDEH A., ZARI M.P., BROWN D.K. Components of landscape pattern and urban biodiversity in an era of climate change: a global survey of expert knowledge. Urban Ecosystems, 21 (5), 903, 2018.

25. ERENER A. Remote sensing of vegetation health for reclaimed areas of Seyitömer open cast coal mine. International Journal of Coal Geology, 86 (1), 20, 2011.

26. LIAO X., LI W., HOU J. Application of GIS based ecological vulnerability evaluation in environmental impact assessment of master plan of coal mining area. Procedia Environmental Sciences, 18 (18), 271, 2013.

27. QIAN D., YAN C., XING Z., XIU L. Monitoring coal mine changes and their impact on landscape patterns in an alpine region: a case study of the Muli coal mine in the Qinghai-Tibet Plateau. Environmental Monitoring and Assessment, 189 (11), 559, 2017.

28. LEI S., REN L.X., BIAN Z. Time-space characterization of vegetation in a semiarid mining area using empirical orthogonal function decomposition of MODIS NDVI time series. Environmental Earth Sciences, 75 (6), 516, 2016.

29. LATIFOVIC R., FYTAS K., CHEN J. PARASZCAK J. Assessing land cover change resulting from large surface mining development. International Journal of Applied Earth Observation and Geoinformation, 7 (1), 29, 2005.

30. CAO Y.G., ZHANG X.R., BAI Z.K., ZHOU W., CHEN X.H., SUN Q., DING X. Temporal- spatial transformation characteristics of land use types in composite area of ore-agriculture-urban in Loess Area. Transactions of the Chinese Society of Agricultural Engineering, 31 (7), 238, 2015 [In Chinese].

31. XU J.X., LI G., CHEN G.L. Driving force analysis of land use change based on Logistic regression model in mining area. Transactions of the Chinese Society of Agricultural Engineering, 28 (20), 247, 2012 [In Chinese].

32. BIAN Z.F., LU Q. Ecological effects analysis of land use change in coal mining area based on ecosystem service valuing: a case study in Jiawang. Environmental Earth Sciences, 68 (6), 1619, 2013.

33. YAN C.D., DAI H.J., GUO W. Evaluation of Ecological Environmental Quality in a Coal Mining Area by Modelling Approach. Sustainability, 9 (8), 1265, 2017.

34. LIU X., LIU W.K., ZHANG H.B., NIU H.P. Comprehensive landscape ecology stability assessment of a coal gangue backfill reclamation area. Polish Journal of Environmental Studies, 25 (3), 1305, 2016.

35. HU Z.Q., XIAO W., WANG P.J., ZHAO Y.L. Concurrent mining and reclamation for underground coal mining. Journal of China Coal Society, 38 (2), 301, 2013 [In Chinese].

36. HOU H.P., ZHANG S.L., DING Z.Y., HUANG A., TIAN Y. Spatiotemporal dynamics of carbon storage in terrestrial ecosystem vegetation in the Xuzhou coal mining area, China. Environmental Earth Sciences, 74 (2), 1657, 2015.

37. ZHOU T., WU J., PENG S. Assessing the effects of landscape pattern on river water quality at multiple scales: A case study of the Dongjiang River watershed, China. Ecological Indicators, 23 (4), 166, 2012.

38. SOFFIANIAN A., MADANIAN M. Monitoring land cover changes in Isfahan Province, Iran using Landsat satellite data. Environmental Monitoring and Assessment, 187 (8), 543, 2015.

39. DUAN N., LIU X.D., DAI J., LIN C.Q., XIA X.H., CAO R.Y., WANG Y., CHEN S.Q., YANG J., QI J. Evaluating the environmental impacts of an urban wetland park based on emergy accounting and life cycle assessment: A case study in Beijing. Ecological Modelling, 222 (2), 351, 2017.

40. LÜ Y.H., FENG X.M., CHEN L.D., FU B.J. Scaling effects of landscape metrics: a comparison of two methods. Physical Geography, 34 (1), 40, 2013.

41. ŠÍMOVÁ, P., GDULOVÁ K. Landscape indices behavior: A review of scale effects. Applied Geography, 34, 385, 2012.

42. MARIANOP G., MARINA B. Regional abundance of a planthopper pest: the effect of host patch area and configuration. Entomologia Experimentalis Applicata. 122 (2), 133, 2007.

43. BOGAERT J., MYNENI R.B., KNYAZIKHIN Y. A mathematical comment on the formulae for the aggregation index and the shape index. Landscape Ecology, 17 (1), 87, 2002.

44. GOCIC M., TRAJKOVIC S. Analysis of changes in meteorological variables using Mann-Kendall and Sen's slope estimator statistical tests in Serbia. Global and Planetary Change, 100 (1), 172, 2013.

45. YUE S., PILON P., PHINNEY B., CAVADIAS G. The influence of autocorrelation on the ability to detect trend in hydrological series. Hydrological Processes, 16 (9), 1807, 2002.

46. TABARI H., SOMEE B.S., ZADEH M.R. Testing for long-term trends in climatic variables in Iran. Atmospheric Research, 100 (1), 132, 2011.

47. JIANG Y., PENG Q.D., LUO H.H., MA W. Analysis of spatial and temporal variation of water quality in Huaihe River Basin. Journal of Hydraulic Engineering, 42 (11), 1283, 2011 [In Chinese].

48. MAO M., CHIRWA E.C. Application of grey model GM $(1,1)$ to vehicle fatality risk estimation. Technological Forecasting and Social Change, 73 (5), 588, 2006.

49. LI D.M., WANG D.Y., LI H., ZHANG S.W., TIAN W.B. The effects of rural settlement evolution on the surrounding land ecosystem service values: a case study in the eco-fragile areas, China. ISPRS International Journal of Geo-Information, 6, 49, 2017.

50. ZHANG Z.M., GAO J.F., GAO Y.N. The influences of land use changes on the value of ecosystem services in Chaohu Lake Basin, China. Environmental Earth Sciences, 74 (1), 385, 2015.

51. XUAN D., XU J. Grout injection into bed separation to control surface subsidence during longwall mining under villages: case study of Liudian coal mine, China. Natural Hazards, 73 (2), 883, 2014. 